\title{
Reduction of circulating superoxide dismutase activity in type 2 diabetic patients with microalbuminuria and its modulation by telmisartan therapy
}

\author{
Hiroki Fujita ${ }^{1}$, Takuya Sakamoto ${ }^{2}$, Koga Komatsu ${ }^{2}$, Hiromi Fujishima ${ }^{1}$, Tsukasa Morii ${ }^{1}$, Takuma Narita ${ }^{1}$, \\ Takamune Takahashi ${ }^{3}$ and Yuichiro Yamada ${ }^{1}$
}

Growing evidence indicates that oxidative stress induced by excessive superoxide has a central role in the pathogenesis of diabetic nephropathy (DN). Telmisartan, one of the currently available angiotensin II type 1 receptor blockers (ARBs), has been shown to exert a more powerful proteinuria (albuminuria) reduction in patients with DN, but whether the prominent renoprotective effect of telmisartan is mediated through enhancing antioxidant defense capacity and reducing oxidative stress has not been fully elucidated. The present study first revealed that the serum activity of superoxide dismutase (SOD) responsible for superoxide removal is reduced in the DN stage of microalbuminuria, but not in normoalbuminuria in type 2 diabetic patients. We next examined the alteration of SOD and oxidative stress following an 8-week treatment with telmisartan ( $40 \mathrm{mg}$ per day) in 12 type 2 diabetic patients with microalbuminuria. Interestingly, the telmisartan treatment not only reduced the circulating levels of two oxidative stress markers, 8-hydroxy-2'-deoxyguanosine (8-OHdG) and nitrotyrosine (NT), but also enhanced serum SOD activity. Notably, a significant correlation was observed between the increase in serum SOD activity and the reduction in albuminuria. We further compared the anti-oxidative effect of telmisartan with that of losartan, another member of the ARB class, by implementing an 8-week interval crossover treatment with these ARBs in another 12 microalbuminuric type 2 diabetic patients. The patients showed higher serum SOD activity, and lower circulating levels of 8-OHdG and NT, during treatment with telmisartan than with losartan. These results suggest that telmisartan has a more potent antioxidative effect through its ability to enhance SOD activity in type 2 diabetic patients with microalbuminuria.

Hypertension Research (2011) 34, 1302-1308; doi:10.1038/hr.2011.127; published online 4 August 2011

Keywords: angiotensin II type 1 receptor blocker; diabetic nephropathy; oxidative stress; superoxide dismutase; telmisartan

\section{INTRODUCTION}

Oxidative stress induced by superoxide anion $\left(\mathrm{O}_{2}{ }^{\bullet-}\right)$ overproduction is considered a major cause of diabetic vascular injury, including diabetic nephropathy (DN). An excess of the superoxide anion causes vascular cell injury through the formation of cytotoxic secondary reactive oxygen species, such as peroxynitrite $\left(\mathrm{ONOO}^{-}\right)$and hydroxyl radicals $\left({ }^{\bullet} \mathrm{OH}\right){ }^{1}$ The superoxide is produced by multiple pathogenic pathways, including increased nicotinamide adenine dinucleotide phosphate $(\mathrm{NAD}(\mathrm{P}) \mathrm{H})$ oxidase activity, uncoupled endothelial nitric oxide (NO) synthase and enhanced angiotensin II signaling. ${ }^{2}$ In contrast to the superoxide-producing enzymes such as $\mathrm{NAD}(\mathrm{P}) \mathrm{H}$ oxidase and endothelial NO synthase, superoxide dismutase (SOD) serves as an antioxidant enzyme responsible for superoxide removal. The SOD converts superoxide anion into hydrogen peroxide $\left(\mathrm{H}_{2} \mathrm{O}_{2}\right)$ and molecular oxygen., ${ }^{3,4}$ The hydrogen peroxide is further detoxified into water $\left(\mathrm{H}_{2} \mathrm{O}\right)$ by catalase in peroxisomes or glutathione peroxidase in mitochondria. ${ }^{1,5}$ Growing evidence indicates that chronic hyperglycemia causes superoxide overproduction by activating $\mathrm{NAD}(\mathrm{P}) \mathrm{H}$ oxidase $\mathrm{o}^{6-9}$ and uncoupling endothelial NO synthase. ${ }^{9}$ Therefore, the SOD antioxidant defense system has a key role in protecting vascular cells from increased oxidative stress in the diabetic state.

Telmisartan is a unique angiotensin II type 1 (AT1) receptor blocker (ARB) that functions as a partial agonist of the peroxisome proliferator-activated receptor- $\gamma \cdot{ }^{10-12}$ A recent clinical study showed that telmisartan is superior to another ARB, losartan, in reducing proteinuria effect in patients with DN, despite a comparable blood pressure reduction. ${ }^{13}$ Given this compelling evidence, it was expected that telmisartan, among various ARBs, may exert a more powerful protective effect against oxidative stress in the diabetic state. In the present study, we first determined the stage of DN that alters the SOD antioxidant defense capacity and enhances oxidative stress. Our data demonstrate that reduced SOD antioxidant defense capacity and markedly increased oxidative stress are observed in the DN stage of

${ }^{1}$ Division of Endocrinology, Metabolism and Geriatric Medicine, Akita University Graduate School of Medicine, Akita, Japan; ${ }^{2}$ Division of Gastroenterology, Honjo Daiichi Hospital, Akita, Japan and ${ }^{3}$ Division of Nephrology, Vanderbilt University Medical Center, Nashville, TN, USA

Correspondence: Dr H Fujita, Division of Endocrinology, Metabolism and Geriatric Medicine, Akita University Graduate School of Medicine, 1-1-1 Hondo, Akita 010-8543, Japan. E-mail: hirofuji@gipc.akita-u.ac.jp

Received 29 January 2011; revised 13 May 2011; accepted 6 June 2011; published online 4 August 2011 
microalbuminuria, but not in the normoalbuminuria stage, which indicates that the microalbuminuric DN stage would be more suitable for antioxidative intervention. Based on this observation, the aim of the present study was to determine the effects of telmisartan therapy on the SOD antioxidant defense system and on the three oxidative stress markers, 8-hydroxy-2'-deoxyguanosine (8-OHdG), NO and nitrotyrosine $(\mathrm{NT})$, in patients in the microalbuminuric DN stage.

\section{METHODS}

\section{Subjects and study protocols}

The study participants were Japanese residents of Akita prefecture, Japan. First, we recruited 18 non-diabetic healthy (control) subjects and 35 type 2 diabetic patients (19 normoalbuminuric patients and 16 microalbuminuric patients) ,who had not been treated with anti-hypertensive drugs, thiazolidine, metformin, statins and fenofibrate. Persistent microalbuminuria was defined as a urinary albumin-to-creatinine ratio between 30 and $300 \mathrm{mgg}^{-1}$ creatinine in two morning spot urine collections performed over 3 months. The diabetic patients were under treatment with sulfonylurea and/or $\alpha$-glucosidase inhibitor or dietary therapy alone to control their blood glucose. Morning blood and spot urine samples were collected from these subjects to determine oxidative stress markers, including 8-OHdG, SOD, NO and NT. Serum and urinary levels of the oxidative stress markers were compared among the three groups: the control subjects, the normoalbuminuric diabetic patients and the microalbuminuric diabetic patients. We treated 12 of the 16 microalbuminuric diabetic patients with telmisartan $40 \mathrm{mg}$ per day for 8 weeks. The doses of anti-diabetic medications were unchanged during the telmisartan treatment period. The serum and urinary levels of the oxidative stress markers after 8 weeks of telmisartan treatment were compared with those before the treatment.

For the crossover study of telmisartan and losartan, we next recruited another 12 microalbuminuric type 2 diabetic patients who had been treated with telmisartan $40 \mathrm{mg}$ per day for more than 8 weeks. None of the patients had been given other anti-hypertensive drugs, such as angiotensin-converting enzyme inhibitors, calcium channel blockers or diuretics. The patients were given sulfonylurea and/or $\alpha$-glucosidase inhibitor to control their blood glucose. The anti-diabetic therapy was unchanged during the study. This crossover study consisted of three treatment periods: telmisartan $40 \mathrm{mg}$ per day for 8 weeks (first period), losartan $50 \mathrm{mg}$ per day for 8 weeks (second period) and telmisartan $40 \mathrm{mg}$ per day for 8 weeks (third period). After being recruited, the patients continued taking telmisartan $40 \mathrm{mg}$ per day for 8 weeks. Thereafter, the patients were crossed over to the ARB treatment with losartan $50 \mathrm{mg}$ per day for 8 weeks, and then to the treatment with telmisartan $40 \mathrm{mg}$ per day for 8 weeks, without a wash-out period between the treatment periods. The serum and urinary levels of the oxidative stress markers were determined at the end of each treatment period.

The study protocols were approved by the Ethics Committees of Akita University and Honjo Daiichi Hospital. Written informed consent was obtained from all participants.

\section{Measurements}

The serum/plasma and urine samples were stored at $-80^{\circ} \mathrm{C}$ until assays were performed. The hemoglobin Alc levels, measured using high-performance liquid chromatography, were expressed as international standard values (Japan Diabetes Society standard value $+0.4 \%$ ), as defined by the Japan Diabetes Society. The serum and urinary $8-\mathrm{OHdG}$ levels were measured using an enzyme-linked immunosorbent assay kit (8-OHdG Check; Nikken Seil, Shizuoka, Japan). Serum SOD activity was determined using an SOD assay kitWST (Dojindo Molecular Technologies, Gaithersburg, MD, USA). Serum NOx (nitrite+nitrate) and NT concentrations were measured by a total NO assay kit (Stressgen, Ann Arbor, MI, USA) and an NT enzyme-linked immunosorbent assay kit (NWLSS, Vancouver, WA, USA), respectively.

\section{Statistical analysis}

Data were presented as the mean \pm s.d. Statistical analysis was performed using GraphPad Prism software (GraphPad, San Diego, CA, USA). Differences between multiple groups were determined by one-way ANOVA, followed by
Bonferroni's multiple comparison test. Data from the telmisartan treatment study and the crossover study of telmisartan and losartan were statistically analyzed by paired $t$-test. A value of $P<0.05$ denoted the presence of a statistically significant difference.

\section{RESULTS}

Oxidative stress markers in control subjects and type 2 diabetic patients with normoalbuminuria and microalbuminuria

Table 1 shows clinical and biochemical parameters in the control subjects and the type 2 diabetic patients with normoalbuminuria and microalbuminuria. Both groups of diabetic patients exhibited higher systolic blood pressure, higher levels of fasting plasma glucose and hemoglobin Alc, and lower levels of high-density lipoprotein cholesterol relative to the control subjects. There were no significant differences in blood pressure, plasma glucose and serum lipid levels between the two groups of type 2 diabetic patients with normoalbuminuria and microalbuminuria. Interestingly, a reduction in serum SOD activity was observed in the diabetic patients with microalbuminuria (Figure 1a). Furthermore, analysis of oxidative stress markers revealed a significant increase in serum and urinary $8-\mathrm{OHdG}$ levels and in serum NT levels that reflected the degree of oxidative stress in the diabetic patients with microalbuminuria, compared with the other groups (Figures 1b-d). As shown in Figure 1e, serum NOx levels were significantly reduced in the diabetic patients with microalbuminuria, compared with the other groups.

The effects of telmisartan treatment on oxidative stress markers in type 2 diabetic patients with microalbuminuria

Because increased systemic oxidative stress was shown to be caused during the microalbuminuria stage, possibly through impaired antioxidant defense capacity such as reduced serum SOD activity, we next investigated whether telmisartan treatment attenuates increased oxidative stress in type 2 diabetic patients with microalbuminuria. Table 2 shows clinical and biochemical parameters at baseline and after 8 weeks of telmisartan treatment ( $40 \mathrm{mg}$ per day) in type 2 diabetic patients with microalbuminuria. The 8 -week telmisartan treatment did not alter body mass index, plasma glucose or serum lipid levels.

Table 1 Clinical parameters in control subjects and type 2 diabetic patients with normoalbuminuria and microalbuminuria

\begin{tabular}{|c|c|c|c|}
\hline & \multirow[b]{2}{*}{$\begin{array}{l}\text { Control } \\
\text { subjects }\end{array}$} & \multicolumn{2}{|c|}{ Type 2 diabetic patients } \\
\hline & & $\begin{array}{c}\text { Normo- } \\
\text { albuminuria }\end{array}$ & $\begin{array}{c}\text { Micro- } \\
\text { albuminuria }\end{array}$ \\
\hline$n$ & 18 & 19 & 16 \\
\hline Age (years) & $58 \pm 2$ & $61 \pm 5$ & $61 \pm 6$ \\
\hline Gender (male/female) & $11 / 7$ & $13 / 6$ & $10 / 6$ \\
\hline Body mass index $\left(\mathrm{kg} \mathrm{m}^{-2}\right)$ & $22.4 \pm 2.5$ & $23.6 \pm 2.1$ & $25.3 \pm 2.3^{*}$ \\
\hline Systolic blood pressure (mm Hg) & $122 \pm 11$ & $133 \pm 15^{\dagger}$ & $138 \pm 13^{*}$ \\
\hline Diastolic blood pressure (mm Hg) & $79 \pm 5$ & $76 \pm 8$ & $75 \pm 12$ \\
\hline Fasting plasma glucose $\left(\mathrm{mg} \mathrm{dl}^{-1}\right)$ & $99 \pm 8$ & $118 \pm 17^{*}$ & $124 \pm 19 \ddagger$ \\
\hline $\mathrm{HbA1c}(\%)$ & $5.4 \pm 0.3$ & $7.2 \pm 0.3^{\ddagger}$ & $7.3 \pm 0.6^{\ddagger}$ \\
\hline LDL-cholesterol (mg dl-1) & $94.1 \pm 15.4$ & $85.5 \pm 25.5$ & $103.3 \pm 30.4$ \\
\hline HDL-cholesterol (mg dl-1) & $71.1 \pm 9.0$ & $56.7 \pm 14.3^{\ddagger}$ & $53.6 \pm 9.6^{\ddagger}$ \\
\hline Triglyceride (mg dl-1) & $96.4 \pm 57.7$ & $146.1 \pm 89.8$ & $135.3 \pm 72.0$ \\
\hline Serum creatinine $\left(\mathrm{mg} \mathrm{dl}^{-1}\right)$ & $0.68 \pm 0.09$ & $0.71 \pm 0.12$ & $0.69 \pm 0.18$ \\
\hline Urinary albumin ( $\mathrm{mg} \mathrm{g}^{-1}$ creatinine) & $6.9 \pm 5.0$ & $11.0 \pm 4.4$ & $100.2 \pm 52.3 \pm \$$ \\
\hline
\end{tabular}

Abbreviations: HbAlc, hemoglobin Alc; HDL, high-density lipoprotein; LDL, low-density lipoprotein.

Data were presented as means \pm s.d. ${ }^{*} P<0.01,{ }^{\dagger} P<0.05,{ }^{\ddagger} P<0.001$ vs. control subjects; ${ }^{\S}<0.001$ vs. normoalbuminuria. 


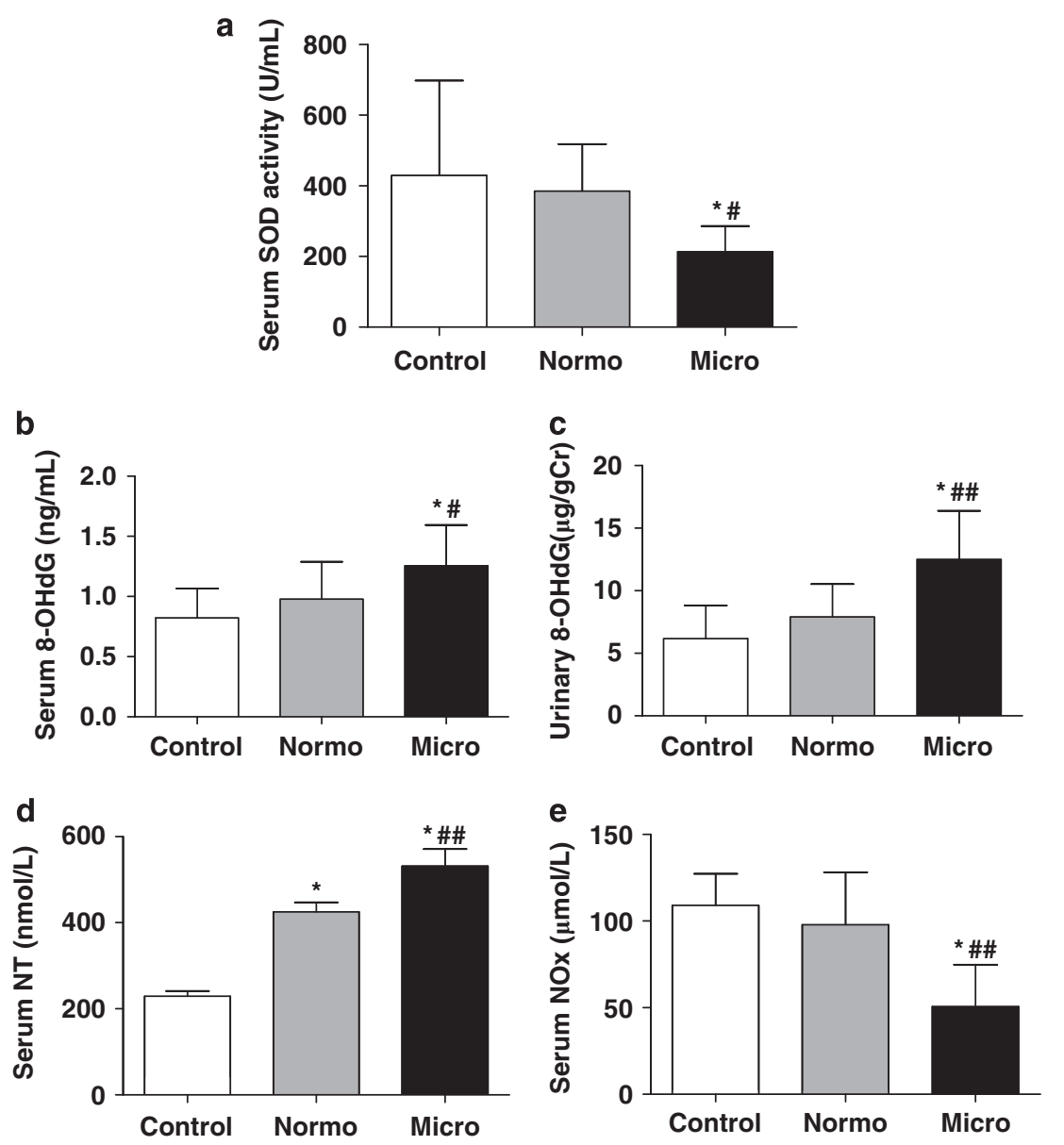

Figure 1 Oxidative stress markers in non-diabetic healthy subjects (control, $n=18$ ) and type 2 diabetic patients with normoalbuminuria (normo, $n=19$ ) and microalbuminura (micro, $n=16$ ). (a) serum SOD activity; (b) serum 8-OHdG; (c) urinary 8-OHdG; (d) serum NT; (e) serum NOx. Data are presented as the means \pm s.d. ${ }^{*} P<0.001$ vs. control; ${ }^{\#} P<0.05$ vs. normo; ${ }^{\#} P<0.001$ vs. normo. NT, nitrotyrosine.

Not surprisingly, the telmisartan treatment lowered systolic and diastolic blood pressure and reduced albuminuria. Figure 2 shows the changes in the oxidative stress markers after 8 weeks of telmisartan treatment in the diabetic patients with microalbuminuria. Notably, an increase in serum SOD activity was observed after 8 weeks of telmisartan treatment (Figure 2a). Interestingly, there was a significant correlation between the increase in serum SOD activity and the reduction in albuminuria (Figure $2 b$ ). In agreement with the improvement in antioxidant defense capacity, serum and urinary $8-\mathrm{OHdG}$ levels and serum NT levels were significantly reduced after 8 weeks of telmisartan treatment (Figures 2c-e). The serum NOx levels were significantly increased after 8 weeks of telmisartan treatment (Figure 2f). Thus, we found that the telmisartan treatment can improve systemically increased oxidative stress and reduce SOD antioxidant defense capacity in microalbuminuric type 2 diabetic patients.

\section{Changes in oxidative stress markers by crossover treatment} with telmisartan and losartan in type 2 diabetic patients with microalbuminuria

To compare the antioxidative effects of telmisartan with those of other ARBs, we performed a crossover treatment with telmisartan and losartan in type 2 diabetic patients with microalbuminuria, and investigated changes in oxidative stress markers. Table 3 shows clinical and biochemical parameters at the end of each 8-week treatment
Table 2 Changes in clinical parameters after 8 weeks of telmisartan treatment in type 2 diabetic patients with microalbuminuria

\begin{tabular}{|c|c|c|}
\hline & Baseline & Telmisartan $8 W$ \\
\hline$n$ & 12 & \\
\hline Age (years) & $64 \pm 7$ & \\
\hline Gender (male/female) & $6 / 6$ & \\
\hline Body mass index $\left(\mathrm{kg} \mathrm{m}^{-2}\right)$ & $24.8 \pm 2.6$ & $24.8 \pm 2.6$ \\
\hline Systolic blood pressure $(\mathrm{mm} \mathrm{Hg})$ & $138 \pm 5$ & $127 \pm 10^{*}$ \\
\hline Diastolic blood pressure (mm Hg) & $73 \pm 7$ & $69 \pm 7^{\dagger}$ \\
\hline Fasting plasma glucose $\left(\mathrm{mg} \mathrm{dl}^{-1}\right)$ & $116 \pm 12$ & $115 \pm 13$ \\
\hline $\mathrm{HbAlc}(\%)$ & $7.2 \pm 0.7$ & $7.2 \pm 0.7$ \\
\hline LDL-cholesterol (mg dl-1) & $97.1 \pm 24.2$ & $92.7 \pm 26.3$ \\
\hline HDL-cholesterol (mg dl-1) & $54.7 \pm 8.8$ & $56.5 \pm 7.9$ \\
\hline Triglyceride (mg dl ${ }^{-1}$ ) & $130.8 \pm 66.7$ & $121.4 \pm 61.5$ \\
\hline Serum creatinine $\left(\mathrm{mg} \mathrm{dl}^{-1}\right)$ & $0.71 \pm 0.16$ & $0.70 \pm 0.14$ \\
\hline Urinary albumin ( $\mathrm{mgg}^{-1}$ creatinine) & $110.5 \pm 72.5$ & $66.8 \pm 59.7^{*}$ \\
\hline
\end{tabular}

Abbreviations: HbAlc, hemoglobin Alc; HDL, high-density lipoprotein; LDL, low-density lipoprotein.

Data were presented as means \pm s.d. ${ }^{*} P<0.001,{ }^{\dagger} P<0.01$ vs. baseline.

period: telmisartan $40 \mathrm{mg}$ per day (first period), losartan $50 \mathrm{mg}$ per day (second period) and telmisartan $40 \mathrm{mg}$ per day (third period). There were no significant differences in body mass index, blood pressure, plasma glucose or serum lipid levels between the three 

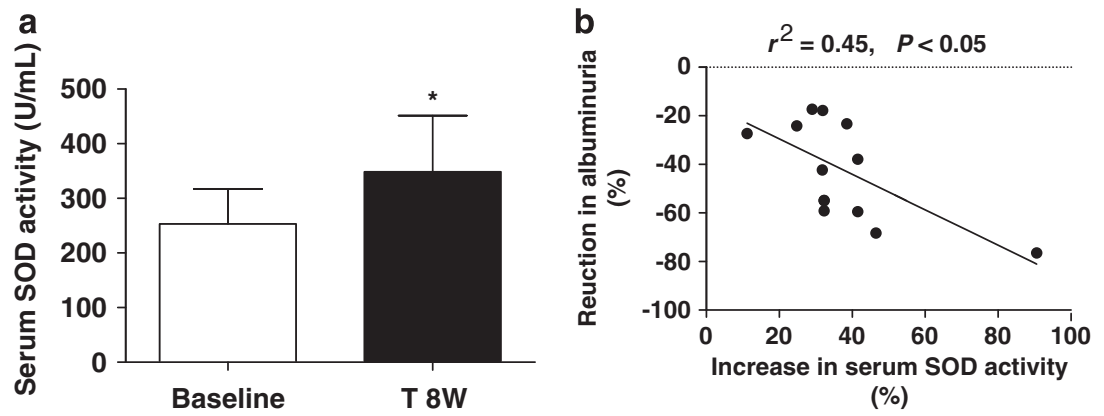

(\%)
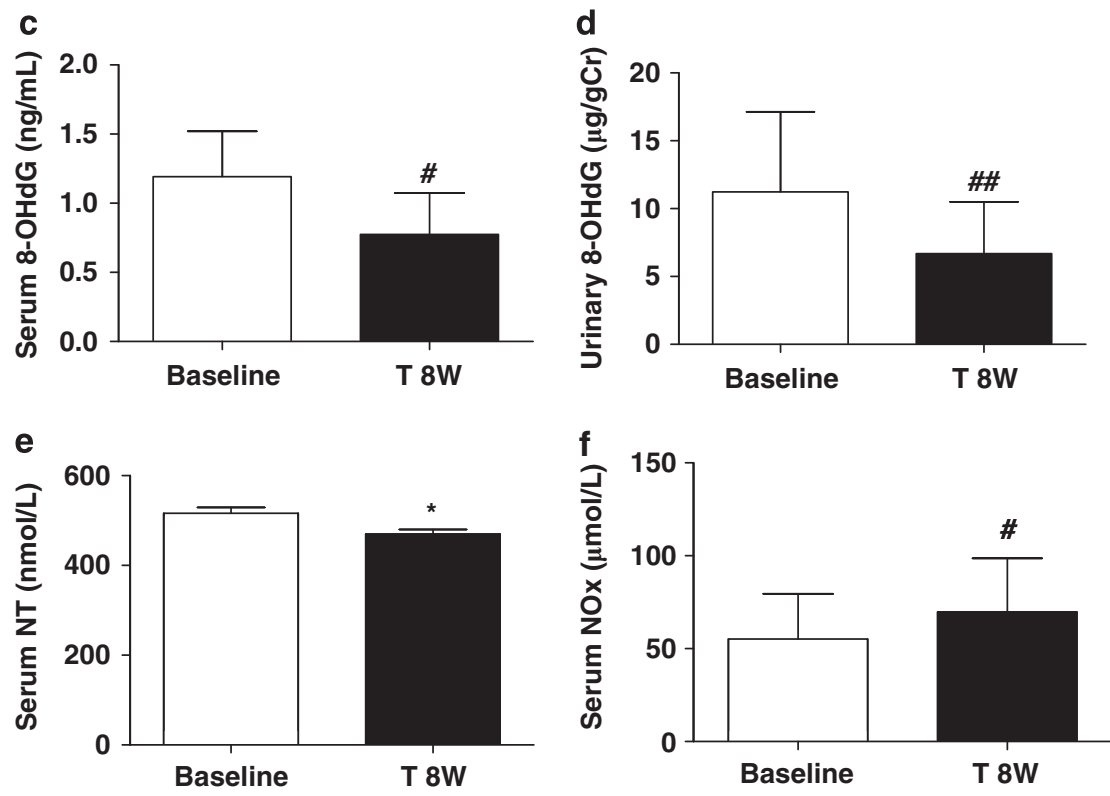

Figure 2 Changes in oxidative stress markers after 8 weeks of telmisartan treatment in type 2 diabetic patients with microalbuminuria. (a) serum SOD activity; (b) correlation between increase in serum SOD activity and reduction in albuminuria; (c) serum 8-OHdG; (d) urinary 8-OHdG; (e) serum NT; (f) serum NOx. Data are presented as the means \pm s.d. $(n=12) .{ }^{*} P<0.001,{ }^{\#} P<0.01,{ }^{\# \#} P<0.05$ vs. baseline. T $8 \mathrm{~W}$, telmisartan treatment for 8 weeks; NT, nitrotyrosine.

treatment periods. A significant increase in albuminuria was observed after the treatment was crossed over from telmisartan to losartan. Furthermore, albuminuria was significantly reduced after the treatment was switched from losartan to telmisartan. Figure 3 shows changes in the oxidative stress markers from the crossover treatment with telmisartan and losartan in the diabetic patients with microalbuminuria. Interestingly, serum SOD activity was significantly higher during the first and third periods of telmisartan treatment than during the second period of losartan treatment (Figure 3a). Consistent with the change in albuminuria, the oxidative stress marker levels of serum and urinary 8-OHdG and serum NT were significantly lower during the first and third periods of telmisartan treatment than during the second period of losartan treatment (Figures 3b-d). Serum NOx levels were significantly elevated in the first and third periods of telmisartan treatment compared with the second period of losartan treatment (Figure 3e).

\section{DISCUSSION}

Various markers of oxidative stress have been identified and clinically used. 8-OHdG is an accepted indicator of oxidative DNA damage, and its levels in serum and urine have been widely measured to monitor the degree of oxidative stress. ${ }^{14,15}$ Plasma/serum NT levels have been used as a marker of oxidative and nitrosative stress and as a specific indicator of systemic peroxynitrite formation. ${ }^{16,17}$ It should be noted that in the present study the levels of serum and urinary 8-OHdG and serum NT were higher in the diabetic patients with microalbuminuria than in those with normoalbuminuria, despite comparable levels of hyperglycemia. These findings indicate that oxidative and nitrosative stress is highly produced in the DN stage of microalbuminuria, but not in the normoalbuminuria stage. Furthermore, we found that serum activity of SOD, which has a central role in the antioxidant defense system, is reduced in the DN stage of microalbuminuria. Experimental studies have shown that excessive superoxide is produced in human aortic endothelial cells by prolonged exposure to high glucose, ${ }^{18}$ and in mouse kidney glomeruli by chronic hyperglycemia. ${ }^{19}$ Therefore, it is conceivable that the capacity of SOD to remove superoxide could be a major determinant of the degree of superoxide-induced oxidative and nitrosative stress under chronic hyperglycemia. Taking these findings together, the reduction of SOD antioxidant defense capacity appears to be responsible for the increased level of oxidative and nitrosative stress in the DN stage of microalbuminuria. Thus, the microalbuminuric DN stage is thought to be more suitable than other stages for antioxidative intervention.

Telmisartan has been shown to produce a proteinuria (albuminuria)-reducing effect in patients with overt $\mathrm{DN}^{20}$ and to reduce the transition from incipient to overt DN. ${ }^{21}$ However, whether the mechanism underlying these renoprotective effects afforded by telmisartan involves the reduction of oxidative stress is not fully under- 
Table 3 Changes in clinical parameters by crossover treatment with telmisartan and losartan in type 2 diabetic patients with microalbuminuria

\begin{tabular}{|c|c|c|c|}
\hline & $\begin{array}{c}\text { First } \\
\text { period } \\
\text { telmisartan } \\
8 W\end{array}$ & $\begin{array}{c}\text { Second } \\
\text { period } \\
\text { losartan } \\
8 W\end{array}$ & $\begin{array}{c}\text { Third } \\
\text { period } \\
\text { telmisartan } \\
8 W\end{array}$ \\
\hline$n$ & 12 & & \\
\hline Age (years) & $68 \pm 6$ & & \\
\hline Gender (male/female) & $5 / 7$ & & \\
\hline Body mass index $\left(\mathrm{kg} \mathrm{m}^{-2}\right)$ & $23.9 \pm 3.7$ & $23.7 \pm 3.8$ & $23.8 \pm 3.8$ \\
\hline Systolic blood pressure $(\mathrm{mm} \mathrm{Hg})$ & $126 \pm 12$ & $132 \pm 13$ & $128 \pm 11$ \\
\hline Diastolic blood pressure $(\mathrm{mm} \mathrm{Hg})$ & $69 \pm 8$ & $75 \pm 8$ & $71 \pm 7$ \\
\hline Fasting plasma glucose $\left(\mathrm{mg} \mathrm{dl}^{-1}\right)$ & $113 \pm 13$ & $119 \pm 17$ & $115 \pm 17$ \\
\hline $\mathrm{HbAlc}(\%)$ & $6.5 \pm 0.8$ & $6.6 \pm 0.9$ & $6.6 \pm 0.9$ \\
\hline LDL-cholesterol ( $\left.\mathrm{mg} \mathrm{dl}^{-1}\right)$ & $107.9 \pm 24.7$ & $107.9 \pm 24.5$ & $110.0 \pm 24.5$ \\
\hline HDL-cholesterol $\left(\mathrm{mg} \mathrm{dl}^{-1}\right)$ & $59.8 \pm 14.7$ & $58.6 \pm 14.6$ & $58.2 \pm 13.5$ \\
\hline Triglyceride $\left(\mathrm{mg} \mathrm{dl}^{-1}\right)$ & $86.3 \pm 38.4$ & $72.4 \pm 25.2$ & $79.7 \pm 22.7$ \\
\hline Serum creatinine $\left(\mathrm{mg} \mathrm{dl}^{-1}\right)$ & $0.65 \pm 0.19$ & $0.61 \pm 0.15$ & $0.62 \pm 0.15$ \\
\hline Urinary albumin (mgg ${ }^{-1}$ creatinine) & $68.4 \pm 38.5$ & $86.0 \pm 53.1^{*}$ & $73.5 \pm 49.3^{\dagger}$ \\
\hline
\end{tabular}

Abbreviations: HbAlc, hemoglobin Alc; HDL, high-density lipoprotein; LDL, low-density lipoprotein.

Data were presented as means \pm s.d. ${ }^{*} P<0.05$ vs. first period; ${ }^{\dagger} P<0.05$ vs. second period. stood. Recent experimental studies have shown that telmisartan attenuates oxidative stress by downregulating $\mathrm{NAD}(\mathrm{P}) \mathrm{H}$ oxidase, a major superoxide-producing enzyme..$^{22,23}$ By contrast, the effect of telmisartan on a superoxide-scavenging enzyme, SOD, has not been clarified. Therefore, we next tested whether telmisartan treatment ameliorates the reduced SOD antioxidant defense capacity in the DN stage of microalbuminuria. Our data clearly demonstrate that telmisartan treatment enhances serum SOD activity and systemically reduces oxidative and nitrosative stress in patients with microalbuminuric DN. Importantly, the increase in serum SOD activity by telmisartan treatment showed a correlation with the reduction of albuminuria in these patients with microalbuminuric DN. This finding indicates that the mechanism by which telmisartan provides renoprotective effects may involve improvement of the SOD antioxidant defense capacity. Considering the present results along with recent compelling evidence, it is likely that telmisartan exerts antioxidative effects by modulating both superoxide-producing and superoxide-scavenging enzymes.

Angiotensin II has been shown to promote superoxide generation through $\mathrm{NAD}(\mathrm{P}) \mathrm{H}$ oxidase activation, independently of its systemic vasoconstriction ability. ${ }^{24,25}$ Therefore, blockade of the angiotensin II signaling pathway via AT1 receptors is expected to reduce the superoxide-induced oxidative stress. Although all ARBs may share the antioxidative effects to some extent, there seems to be a difference

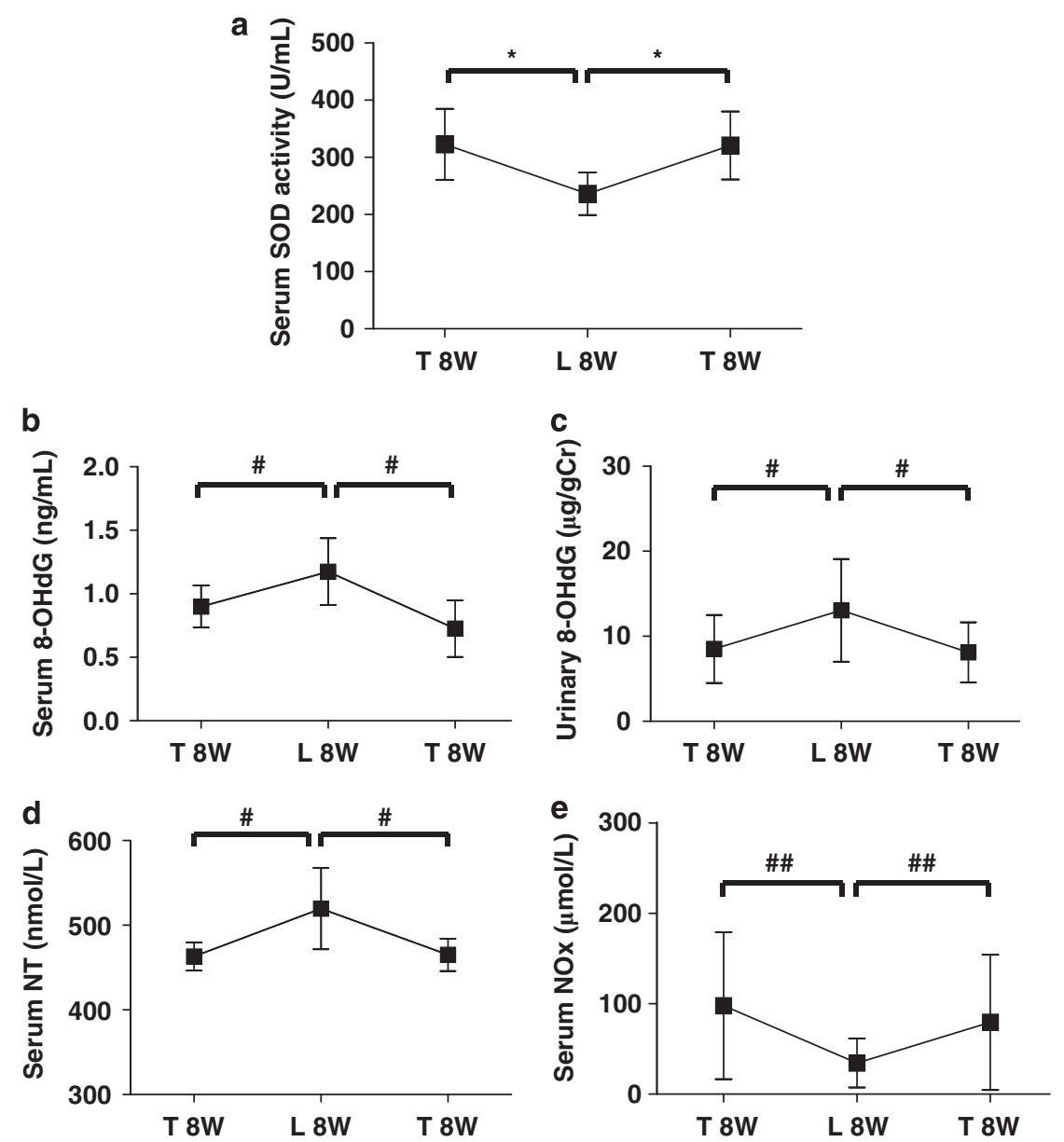

Figure 3 Changes in oxidative stress markers by crossover treatment with telmisartan and losartan in type 2 diabetic patients with microalbuminuria. (a) serum SOD activity; (b) serum 8-OHdG; (c) urinary 8-OHdG; (d) serum NT; (e) serum NOx. Data are presented as the means \pm s.d. ( $n=12$ ). ${ }^{*} P<0.01$, ${ }^{\#} P<0.001$, ${ }^{\#} P<0.05$. T 8W, telmisartan treatment for 8 weeks; L 8W, losartan treatment for 8 weeks; NT, nitrotyrosine. 
in their ability to ameliorate oxidative stress owing to their intrinsic pharmacokinetic and physiochemical properties. Telmisartan has the strongest binding affinity to AT1 receptors, the longest plasma half-life and the highest lipophilicity of currently available ARBs. ${ }^{26,27}$ These properties of telmisartan may be important for long-lasting antioxidative effects. In the present study, we further compared the antioxidative effects between two ARBs, telmisartan and losartan, via crossover treatment with these ARBs in type 2 diabetic patients with microalbuminuria. Our data clearly demonstrate that telmisartan is superior to losartan in reducing oxidative and nitrosative stress, despite comparable levels of blood pressure, plasma glucose and serum lipids. Furthermore, we found that serum activity of SOD, a major antioxidant defense enzyme, is higher during treatment with telmisartan than with losartan. As shown in recent clinical studies of type 2 diabetic patients, telmisartan exerts more powerful effects on the reduction of proteinuria (albuminuria) than do losartan ${ }^{13}$ and valsartan. ${ }^{28}$ This may be attributable in part to the prominent antioxidative effects of telmisartan.

It would be valuable to elucidate the mechanism underlying the upregulation of SOD induced by telmisartan. Because NAD $(\mathrm{P}) \mathrm{H}$ oxidase has been closely linked to SOD in the signaling pathway, this enzyme may negatively regulate SOD. It is thought that telmisartan markedly inhibits $\mathrm{NAD}(\mathrm{P}) \mathrm{H}$ oxidase through its strong binding affinity to AT1 receptors. Furthermore, the action of telmisartan as a partial agonist for peroxisome proliferator-activated receptor- $\gamma$ probably contributes to inhibition of $\mathrm{NAD}(\mathrm{P}) \mathrm{H}$ oxidase. In fact, an experimental study of obese and hypertensive rats has indicated that peroxisome proliferator-activated receptor- $\gamma$ activation by pioglitazone therapy downregulates $\mathrm{NAD}(\mathrm{P}) \mathrm{H}$ oxidase. ${ }^{29}$ Thus, telmisartan may upregulate SOD via strong suppression of $\mathrm{NAD}(\mathrm{P}) \mathrm{H}$ oxidase. Further efforts are required to elucidate this molecular mechanism.

NO has an important role in maintaining renal vascular endothelial function involved in the regulation of urinary albumin excretion. A recent clinical study reported that blood NO levels were decreased in type 2 diabetic patients with overt $\mathrm{DN}$, compared with non-diabetic control subjects. ${ }^{30}$ Consistent with this observation, our study also demonstrated a reduction in serum NO levels in the diabetic patients with incipient DN relative to those without DN and the non-diabetic control subjects. Indeed, NO may be extremely important for renoprotection in the diabetic state. Recent experimental studies of diabetic rats and mice have indicated that decreased renal NO levels are associated with the development of renal histologic lesions ${ }^{31}$ and that NO deficiency by endothelial NO synthase knockout causes glomerular endothelial injury and overt albuminuria. ${ }^{32}$ The reduction of circulating $\mathrm{NO}$ in the microalbuminuric stage of $\mathrm{DN}$ observed in the present study was probably attributed to the direct scavenging of NO by excessive superoxide, because serum NT levels, which reflect the formation of peroxynitrite by chemical interaction of superoxide with NO, were enhanced in this stage. This concept is supported by the present results; the attenuation of oxidative stress by telmisartan treatment, which reflects the reduction in superoxide, led to the increase in serum NO levels and the reduction in serum NT levels. A recent clinical study demonstrated improvement of vascular endothelial function after telmisartan treatment in type 2 diabetic patients by measuring flow-mediated vasodilation. ${ }^{33}$ Thus, the increase in circulating NO following the reduction of hyperglycemia-induced oxidative stress by telmisartan treatment is thought to contribute to renoprotection, including an albuminuriareducing effect via amelioration of renal glomerular endothelial function.
In conclusion, we here report a novel finding that telmisartan has a more powerful antioxidative effect due to its ability to enhance the activity of an antioxidant defense enzyme, SOD. This effect may be attributable to the physiochemical, pharmacological and pharmacokinetic properties of telmisartan. Furthermore, this antioxidative effect of telmisartan may explain why this ARB exerts more potent renoprotection in patients with $\mathrm{DN}$ than other members of the ARB class, such as losartan and valsartan. The dual effects of telmisartan on hypertension and oxidative stress are expected to greatly contribute to improvement of renal outcomes in specific patient populations with $\mathrm{DN}$ that is closely linked to hypertension and oxidative stress.

\section{CONFLICT OF INTEREST}

The authors declare no conflict of interest.

\section{ACKNOWLEDGEMENTS}

This work was supported by a Grant-in-Aid for Scientific Research (no. 20590943 to H. Fujita) from the Ministry of Education, Science and Culture, Japan.

1 Evans JL, Goldfine ID, Maddux BA, Grodsky GM. Oxidative stress and stress-activated signaling pathways: a unifying hypothesis of type 2 diabetes. Endocr Rev 2002; 23 : 599-622.

2 Li JM, Shah AM. Endothelial cell superoxide generation: regulation and relevance for cardiovascular pathophysiology. Am J Physiol Regul Integr Comp Physiol 2004; 287: R1014-R1030.

3 Fridovich I. Superoxide radical and superoxide dismutases. Annu Rev Biochem 1995; 64: 97-112.

4 Fridovich I. Superoxide anion radical (02-.), superoxide dismutases, and related matters. J Biol Chem 1997; 272: 18515-18517.

5 Halliwell B. Antioxidant characterization. Methodology and mechanism. Biochem Pharmacol 1995; 49: 1341-1348.

6 Thallas-Bonke V, Thorpe SR, Coughlan MT, Fukami K, Yap FY, Sourris KC, Penfold SA, Bach LA, Cooper ME, Forbes JM. Inhibition of NADPH oxidase prevents advanced glycation end product-mediated damage in diabetic nephropathy through a protein kinase C-alpha-dependent pathway. Diabetes 2008; 57: 460-469.

7 Gorin Y, Block K, Hernandez J, Bhandari B, Wagner B, Barnes JL, Abboud HE. Nox4 NAD(P)H oxidase mediates hypertrophy and fibronectin expression in the diabetic kidney. J Biol Chem 2005; 280: 39616-39626.

8 Kitada M, Koya D, Sugimoto T, Isono M, Araki S, Kashiwagi A, Haneda M. Translocation of glomerular p47phox and p67phox by protein kinase C-beta activation is required for oxidative stress in diabetic nephropathy. Diabetes 2003; 52: 2603-2614.

9 Satoh M, Fujimoto S, Haruna Y, Arakawa S, Horike H, Komai N, Sasaki T, Tsujioka K, Makino $H$, Kashihara N. NAD(P)H oxidase and uncoupled nitric oxide synthase are major sources of glomerular superoxide in rats with experimental diabetic nephropathy. Am J Physiol Renal Physiol 2005; 288: F1144-F1152.

10 Benson SC, Pershadsingh HA, Ho Cl, Chittiboyina A, Desai P, Pravenec M, Qi N, Wang J, Avery MA, Kurtz TW. Identification of telmisartan as a unique angiotensin II receptor antagonist with selective PPARgamma-modulating activity. Hypertension 2004; 43: 993-1002.

11 Janke J, Schupp M, Engeli S, Gorzelniak K, Boschmann M, Sauma L, Nystrom FH, Jordan J, Luft FC, Sharma AM. Angiotensin type 1 receptor antagonists induce human in-vitro adipogenesis through peroxisome proliferator-activated receptorgamma activation. J Hypertens 2006; 24: 1809-1816.

12 Schupp M, Janke J, Clasen R, Unger T, Kintscher U. Angiotensin type 1 receptor blockers induce peroxisome proliferator-activated receptor-gamma activity. Circulation 2004; 109: 2054-2057.

13 Bakris G, Burgess E, Weir M, Davidai G, Koval S. Telmisartan is more effective than losartan in reducing proteinuria in patients with diabetic nephropathy. Kidney Int 2008; 74: 364-369.

14 Wu LL, Chiou CC, Chang PY, Wu JT. Urinary 8-OHdG: a marker of oxidative stress to DNA and a risk factor for cancer, atherosclerosis and diabetics. Clin Chim Acta 2004; 339: 1-9.

15 Nishikawa T, Sasahara T, Kiritoshi S, Sonoda K, Senokuchi T, Matsuo T, Kukidome D, Wake N, Matsumura T, Miyamura N, Sakakida M, Kishikawa H, Araki E. Evaluation of urinary 8-hydroxydeoxy-guanosine as a novel biomarker of macrovascular complications in type 2 diabetes. Diabetes Care 2003; 26: 1507-1512.

16 Ceriello A, Mercuri F, Quagliaro L, Assaloni R, Motz E, Tonutti L, Taboga C. Detection of nitrotyrosine in the diabetic plasma: evidence of oxidative stress. Diabetologia 2001; 44: 834-838

17 Shishehbor MH, Aviles RJ, Brennan ML, Fu X, Goormastic M, Pearce GL, Gokce N, Keaney Jr JF, Penn MS, Sprecher DL, Vita JA, Hazen SL. Association of nitrotyrosine 
levels with cardiovascular disease and modulation by statin therapy. JAMA 2003; 289: 1675-1680.

18 Cosentino F, Hishikawa K, Katusic ZS, Luscher TF. High glucose increases nitric oxide synthase expression and superoxide anion generation in human aortic endothelial cells. Circulation 1997; 96: 25-28.

19 Fujita H, Fujishima H, Chida S, Takahashi K, Qi Z, Kanetsuna Y, Breyer MD, Harris RC, Yamada Y, Takahashi T. Reduction of renal superoxide dismutase in progressive diabetic nephropathy. J Am Soc Nephrol 2009; 20: 1303-1313.

20 Galle J, Schwedhelm E, Pinnetti S, Boger RH, Wanner C. Antiproteinuric effects of angiotensin receptor blockers: telmisartan versus valsartan in hypertensive patients with type 2 diabetes mellitus and overt nephropathy. Nephrol Dial Transplant 2008; 23: 3174-3183

21 Makino $\mathrm{H}$, Haneda M, Babazono $T$, Moriya $T$, Ito $S$, Iwamoto $\mathrm{Y}$, Kawamori $\mathrm{R}$, Takeuchi M, Katayama S. Prevention of transition from incipient to overt nephropathy with telmisartan in patients with type 2 diabetes. Diabetes Care 2007; 30: 1577-1578.

22 Sugiyama $\mathrm{H}$, Kobayashi $\mathrm{M}$, Wang $\mathrm{DH}$, Sunami $\mathrm{R}$, Maeshima Y, Yamasaki Y, Masuoka N, Kira S, Makino $\mathrm{H}$. Telmisartan inhibits both oxidative stress and renal fibrosis after unilateral ureteral obstruction in acatalasemic mice. Nephrol Dial Transplant 2005; 20: 2670-2680.

23 Takaya T, Kawashima S, Shinohara M, Yamashita T, Toh R, Sasaki N, Inoue N, Hirata K, Yokoyama M. Angiotensin II type 1 receptor blocker telmisartan suppresses superoxide production and reduces atherosclerotic lesion formation in apolipoprotein E-deficient mice. Atherosclerosis 2006; 186: 402-410.

24 Griendling KK, Minieri CA, Ollerenshaw JD, Alexander RW. Angiotensin II stimulates NADH and NADPH oxidase activity in cultured vascular smooth muscle cells. Circ Res 1994; 74: 1141-1148.

25 Rajagopalan S, Kurz S, Munzel T, Tarpey M, Freeman BA, Griendling KK, Harrison DG. Angiotensin II-mediated hypertension in the rat increases vascular superoxide production via membrane NADH/NADPH oxidase activation. Contribution to alterations of vasomotor tone. J Clin Invest 1996; 97: 1916-1923.
26 Kakuta H, Sudoh K, Sasamata M, Yamagishi S. Telmisartan has the strongest binding affinity to angiotensin II type 1 receptor: comparison with other angiotensin II type 1 receptor blockers. Int J Clin Pharmacol Res 2005; 25: 41-46.

27 Burnier M. Telmisartan: a different angiotensin II receptor blocker protecting a different population? J Int Med Res 2009; 37: 1662-1679.

28 Yano Y, Hoshide S, Ishikawa J, Noguchi C, Tukui D, Takanori H, Tada M, Kanemaru Y, Yano A, Ishikawa S, Shimada K, Kario K. The differential effects of angiotensin II type 1 receptor blockers on microalbuminuria in relation to low-grade inflammation in metabolic hypertensive patients. Am J Hypertens 2007; 20: 565-572.

29 Dobrian AD, Schriver SD, Khraibi AA, Prewitt RL. Pioglitazone prevents hypertension and reduces oxidative stress in diet-induced obesity. Hypertension 2004; 43: 48-56.

30 Tessari P, Cecchet D, Cosma A, Vettore M, Coracina A, Millioni R, lori E, Puricelli L, Avogaro A, Vedovato $M$. Nitric oxide synthesis is reduced in subjects with type 2 diabetes and nephropathy. Diabetes 2010; 59: 2152-2159.

31 Prabhakar S, Starnes J, Shi S, Lonis B, Tran R. Diabetic nephropathy is associated with oxidative stress and decreased renal nitric oxide production. J Am Soc Nephrol 2007; 18: 2945-2952.

32 Kanetsuna Y, Takahashi K, Nagata M, Gannon MA, Breyer MD, Harris RC, Takahashi T. Deficiency of endothelial nitric-oxide synthase confers susceptibility to diabetic nephropathy in nephropathy-resistant inbred mice. Am J Pathol 2007; 170: 1473-1484.

33 Wago T, Yoshimoto T, Akaza I, Tsuchiya K, Izumiyama H, Doi M, Hirata Y. Improvement of endothelial function in patients with hypertension and type 2 diabetes after treatment with telmisartan. Hypertens Res 2010; 33: 796-801.

(c)

This work is licensed under the Creative Commons Attribution-NonCommercial-No Derivative Works 3.0

Unported License. To view a copy of this license, visit http://creativecommons.org/licenses/by-nc-nd/3.0 